\title{
Relativism 2: Semantic Content
}

\author{
Max Kölbel (ICREA/Logos, Universitat de Barcelona)
}

(Final version as delivered to PhilCompass typesetters 26 August 2014)

\begin{abstract}
In the pair of articles of which this is the second, I present a set of problems and philosophical proposals that have in recent years been associated with the term "relativism". These problems are related to the question of how we should represent thought and speech about certain topics. The main issue is whether we should model such mental states or linguistic acts as involving representational contents that are absolutely correct or incorrect, or whether, alternatively, their correctness should be thought of as varying with some (more or less surprising) factor.

In the first article, "Relativism 1: Representational Content", I discussed the general issue of relativism about representational content. I argued for the conciliatory view that both relativist and absoutist conceptions of representational content can be legitimate.

In the present continuation, I look in more detail at a special case of the general issue, namely the question of whether semantic contents, i.e. the contents assigned to linguistic utterances in the semantics of natural language, should be construed in an absolutist or in a relativist way.
\end{abstract}

As explained at the end of part 1, there has been much debate in recent years about one specal case of the general issue between relativists and absolutists about representational content: the case of semantic content. ${ }^{1}$ In a number of cases, theorists have been arguing about whether to accommodate certain phenomena of extensional variability by saying that expressions are context-sensitive (i.e. do not express the same contents in all contexts of use), by saying that they are index-sensitive (i.e. express contents that do not have the same extension at each point of evaluation), or by explaining away the apparent extensional variability altogether.

In part 2, I shall sharpen the issues involved in this particular debate, by setting out a more definite theoretical framework and exploring the significance of the choice between relativism and absolutism about semantic content.

\section{A Double-Index Framework}

The notion of semantic content (and the related notion of semantic value) has its home in formal semantics, a discipline within which theorists try to model the meaning properties of natural language expressions. The theoretical aims and methodology of formal semantics for natural languages are not particularly clear and not generally agreed upon amongst semanticists. So let us operate with a relatively standard framework. There is a certain consensus, that giving a semantics for (i.e. modelling) a natural language consists centrally in describing a function that assigns semantic values to expressions of the language in question, and that this assignment will at the very least involve the assignment of some suitable semantic values to

\footnotetext{
${ }^{1}$ See, for example, MacFarlane 2003, 2005a, 2011, 2014; Lasersohn 2005, 2008; Kölbel 2002, 2008b, Egan, Hawthorne \& Weatherson 2005, Egan 2007, 2011, 2012; von Fintel \& Gillies 2008; Recanati 2007; Stojanovic 2007, Stephenson 2007a\&b, 2010; Glanzberg 2007, 2009, Dowell 2011. This is just a small sample of a growing literature.
} 
sentences. ${ }^{2}$ A semantic value is suitable if it is the sort of entity that permits making correct predictions about the natural language utterances that are seen as utterances of these sentences.

The most standard type of semantic theory for modelling context-sensitivity would be a double-index theory in the style of Kaplan (1977). ${ }^{3}$ Such a theory will specify a four-place extension- or denotation function I from a domain $\mathrm{E} \times \mathrm{A} \times \mathrm{C} \times \mathrm{P}^{4}$ into the range $\mathrm{D}$, where $\mathrm{E}$ is the set of expressions of the language, $\mathrm{A}$ is a set of assignment functions, each of which assigns extensions to all variables, $\mathrm{C}$ is a set of contexts, and $\mathrm{P}$ is a set of points of evaluation (also often called "circumstance" or "index"). D is a set of extensions or denotations, which will include at least some truth-values and some individual entities. Thus 'I $(e, a, c, p)$ ' describes the extension (or denotation) of the expression $e$ relative to assignment function $a$, context $c$ and point of evaluation $p .5$

The assignment function argument is needed for the standard Tarskian treatment of quantifiers as variable-binding operators. The extension of variables will vary with the assignment function argument, but the extension of expressions that do not contain unbound variables will be constant with respect to the assignment function argument. $^{6}$

The context argument of $\mathbf{I}$ is needed to model indexical expressions such as "now" or "my" by introducing expressions whose extension varies with the context argument. The set $\mathrm{C}$ of contexts is defined simply as the set of quadruples $\langle w, s, t, l\rangle$ such that $w$ is a possible world, $s$ is an agent, i.e. a potential speaker, $t$ is a time, $l$ is a spatial location and, importantly, $s$ is at $l$ at $t$ in $w$. The intuitive idea is that an utterance of an expression will be associated with a unique context $c \in \mathrm{C}$ so that the extension of the expression at $c$ will reflect the semantic properties of that utterance (e.g. predict the right truth-value for each point of evaluation).

Finally, the point of evaluation argument is needed for the semantics of any intensional operators we may allow, such as, for example, modal operators, propositional attitude verbs or tense operators. Thus, the extension of a predicate like "smiles" may vary with the point of evaluation. For example, if points of evaluation are pairs $\langle w, t>$ of possible worlds and times (as in Kaplan 1977) then the extension of "smiles" at $<w, t>$ should correspond to those entities that smile in possibility $w$ at time $t$.

\footnotetext{
${ }^{2}$ Some semanticists will assign semantic values to all expressions (e.g. Heim \& Kratzer 1998), but most do not require that expressions of all categories be assigned semantic values.

3 The framework I am expounding is a "Kaplan style semantics 2" in the taxonomy of $\$ 4.3$ of Westerståhl 2012. While textbooks (e.g. Chierchia \& McConnell-Ginet 2000) expound frameworks in all relevant respects like Kaplan's, some authors seem to move away from the Kaplanian paradigm, for example by treating context-sensitive expressions as containing unbound variables (see e.g. Stanley 2000). One of the lessons of this article will be that the phenomena that have provoked recent discussions about relativism force us to make some decisions about the basic features of the semantic framework we wish to operate in.

${ }^{4} \mathrm{E} \times \mathrm{A} \times \mathrm{C} \times \mathrm{P}$ is the Cartesian product of the sets $\mathrm{E}, \mathrm{A}, \mathrm{C}$ and $\mathrm{P}$, i.e. it is the set of quadruples $(x 1, x 2$, $x 3, x 4)$, such that $x 1 \in \mathrm{E}, x 2 \in \mathrm{A}, x 3 \in \mathrm{C}, x 4 \in \mathrm{P}$.

${ }^{5}$ I am using standard function notation instead of the more familiar double-bracket notation " $[[e]]^{a, c, p}$ " for the denotation of $e$ at $a, c$, and $p$; or the double-turnstile "I ${ }^{a c p} s$ " for attributing truth to a sentence $s$ at $a, c$, and $p$.

${ }^{6}$ Some authors move away from a pure Kaplanian framework by utilizing variables also for modeling phenomena of context-sensitivity, treating certain context-sensitive expressions as in effect containing unbound variables and contexts as determining an assignment function that evaluates unbound variables. See, e.g. Stanley 2000 or Stojanovic 2007.
} 
The above-mentioned notion of the intension of an expression at a context, and the well-known Kaplanian notions of "character" and "content" can be defined in terms of such a function I. For expressions without unbound variables, the intension (= Kaplanian content) of an expression $e$ at a context $c$ is simply the function from points of evaluation to extensions whose value at a point of evaluation $p$ is $\mathbf{I}(e, a, c, p)$. In other words, for all expressions $e$ that do not contain unbound variables and all $c \in \mathrm{C}$ :

(Int) $\operatorname{Intension}(e, c)=_{\text {def }}$ the function $f$ from P into D such that for all $a \in \mathrm{A}, f(p)=$ $\mathbf{I}(e, a, c, p)$.

The Kaplanian character of an expression is simply the function from $\mathrm{C}$ into intensions, such that the character of an expression assigns to each context the intension of that expression in that context. In other words, for all expressions $e$ without unbound variables:

(Char) Character $(e)=_{\text {def }}$ the function $f$ from $\mathrm{C}$ into the set of functions from $\mathrm{P}$ into $\mathrm{D}$, such that for all $c \in \mathrm{C}, f(e)=\operatorname{Intension}(e, c){ }^{7}$

For illustration, a formal semantics of this sort might include the following clauses concerning the singular term "you" and the predicate "are french." that contribute to the definition of $\mathbf{I}$ :

(You) For all $a \in \mathrm{A}, c \in \mathrm{C}, p \in \mathrm{P}$ :

$\mathbf{I}($ "you", $a, c, p)=\{x \in \mathrm{Ag}: x$ is addressed by $\mathrm{S}(c)$ at $\mathrm{T}(c)$ in $\mathrm{W}(c)\}$

[= the set of people being addressed by the agent of $c$ at the time of $c$ in the world of $c]^{8}$.

(Fre) For all $a \in \mathrm{A}, c \in \mathrm{C}, p \in \mathrm{P}$ :

I("are french", $a, c, p)=\{x \in \mathrm{Ag}: \text { in } \mathrm{W}(p) x \text { is french at } \mathrm{T}(p)\}^{9}$

[ $=$ the set of people that are french in the world of $p$ at the time of $p]$.

These clauses make "you" context-dependent and "are french" index-dependent: the extension of "you" varies with the context of use, but it does not vary with the assignment function or the point of evaluation. The extension of "are french", by contrast, varies with the point of evaluation, so it is index-dependent. If our semantics also includes a compositional clause like this:

(Com) For all singular terms $\alpha$ and all predicates $\beta$, and for all $a \in \mathrm{A}, c \in \mathrm{C}, p \in \mathrm{P}$ : $\mathbf{I}\left(\alpha^{\wedge} \beta, a, c, p\right)=1$ iff $\mathbf{I}(\alpha, a, c, p) \subseteq \mathbf{I}(\beta, a, c, p)^{10}$

\footnotetext{
${ }^{7}$ If we want the notions of intension and character to be defined over all expressions, including those containing free variables, then we should define intension along the following lines:

(Int*) Intension $(e, c)=_{\text {def }}$ the function $f$ from $\mathrm{P} \times \mathrm{A}$ into $\mathrm{D}$ such that for all $a \in \mathrm{A}$, and for all $p \in \mathrm{P}$, $f(a, p)=\mathbf{I}(e, a, c, p)$.

and make the corresponding adjustment in the definition of character.

${ }^{8}$ Typically, semanticists treat singular terms like "you" as having individual objects as extensions. The semantics I am here outlining instead assigns sets of individuals to singular terms. For some advantages of this approach, see Sainsbury 2005. It will play no role for the issues of this paper.

9 " $\mathrm{Ag}$ " stands for the set of agents, and " $\mathrm{S}(\mathrm{x})$ ", " $\mathrm{T}(\mathrm{x})$ " and " $\mathrm{W}(\mathrm{x})$ ", respectively, stand for the agent, the time and the world of $\mathrm{x}$. For the alert reader mentioned in footnote 3: (Fre) is a temporalist axiom as Kaplan might have included it in his system. For an alternative axiom replace the last occurrence of " $p$ " with " $c$ ".

${ }^{10}$ I use " $\wedge$ " as a concatenation sign. So " $\alpha \wedge \beta$ " means the same as " $\alpha$ concatenated with $\beta$ in that order".
} 
then we can derive that the sentence "You are french." is both context-dependent (because of "you") and index-dependent (because of "are french").

Given such a framework, we can recast the three types of view from the last section of part 1: contextualism, relativism and absolutism. A problematic expression seemingly exhibits some extensional variability, e.g. whether an utterance of "licorice is tasty" is correct, appears to depend on the utterer. Relativists and contextualists both accept the appearance (while absolutism rejects it). Both think that when the sentence is uttered by someone whose standard of taste favours licorice, then the utterance is true, while an utterance of it is not true in other cases. However, they disagree as to the nature of this extensional variability. Contextualists (of one sort) will say that the variability is a form of context-dependence, i.e. that the intension expressed varies from context to context, just as with indexical expressions like "you". The relativist will say that the variability is a form of index-dependence, i.e. that the intension expressed by the expression at a given context is non-constant, i.e. varies with some aspect of the point of evaluation. The absolutist will deny the apparent dependence and insist that there is no dependence on the utterer at all (even though there may be standard context- or index-dependence involved in the tense of "is tasty").

A further way of understanding what the contextualist says, but which is not always distinguished clearly ${ }^{11}$, is that "Licorice is tasty" is extensionally variable because of the presence of an unbound variable, so that the sentence exhibits neither context-dependence nor index-dependence, but rather assignment-functiondependence. Here the intension of the sentence is constant, but it is that of an open formula. This is a separate option, so we shall distinguish it. ${ }^{12}$

In summary, then, the issue can be re-cast more precisely as the question whether for a given expression $\mathrm{E}, \mathrm{I}(\mathrm{E}, a, c, p)$ should vary with $a, c$ or $p$, or not at all. ${ }^{13}$

\section{Four Predicates: tastyabs, tastyind, tastyrel and tastyvar $\mathbf{X}_{\mathbf{n}}$}

In this section, I shall articulate the semantic axioms of four predicates, thereby stipulating their semantic properties. These predicates thus defined are candidate models of the natural language predicate "is tasty" as they might be offered, respectively, by an absolutist, an open variable contextualist, an indexical contextualist and a relativist.

Making these stipulations requires interpreting points of evaluation as worldtime-agent triples. Thus, let $\mathrm{P}$ contain all triples $\langle w, t, s\rangle$ such that $w \in \mathrm{W}, t \in \mathrm{T}$ and $s$

\footnotetext{
${ }^{11}$ Stojanovic 2007 (p. 701) clearly characterizes contextualism as a view postulating implicit free variables. A similar position is championed in the related debate concerning unarticulated constituents, for example by Stanley and Szabo 2000 and Stanley 2000.

${ }^{12}$ Index-dependence is usually used to model "shiftable" aspects of extensional variation, i.e. factors on which intensional operators can operate. Thus, in the context of debating alternative ways of modeling factors of variation, the most natural alternative to a form of index-dependence combined with corresponding intensional operators is assignment-dependence (i.e. free variables) with corresponding binding expressions. See, for example King 2003 for a discussion of tense as involving variables and binding.

${ }^{13}$ Given that tastiness, by all accounts, is a temporary and contingent feature, strictly speaking, the absolutist may allow some variation with time and world, and she may construe this either as contextdependence or as index-dependence. However, she will deny the controversial kind of variability, i.e. with the utterer or judge.
} 
$\in \mathrm{Ag} .{ }^{14}$ Let us assume that at any time, any thinker has just one standard of taste, where a standard of taste is minimally something that determines the range of things that the possessor of the standard can correctly judge to be tasty or call "tasty". When an item is in this range, i.e. the range of things that the possessor of a given standard can correctly call "tasty", let us say that the item is agreeable to that standard.

Interpreting points of evaluation in this way does not give the game away: it remains an open question whether there are natural language expressions with intensions that vary in extension with the agent parameter, or whether all such intensions are constant with respect to that parameter.

Let us then consider a singular term "Licorice" and four different predicates we

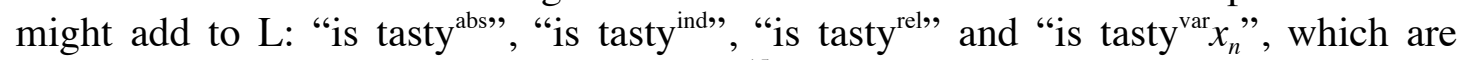
governed by the following semantic axioms ${ }^{15}$ :

For all $a \in \mathrm{A}, c \in \mathrm{C}, p \in \mathrm{P} \ldots$

(Lic) I("Licorice", $a, c, p)=\{x \in \mathrm{D}: x$ is the artificial kind Licorice $\}$ [= the set elements of the domain D that are the artificial kind Licorice].

$\left(\mathrm{T}^{\mathrm{abs}}\right) \quad \mathbf{I}$ ("is tasty $\left.{ }^{\text {abs" }}, a, c, p\right)=\left\{x \in \mathrm{D}\right.$ : in $\mathrm{W}(p) x$ is is tasty ${ }^{\text {abs }}$ at $\left.\mathrm{T}(p)\right\}$ [ $=$ the set of elements of D that are tasty ${ }^{\text {abs }}$ in the world of $p$ at the time of $p$ ].

( $\left.\mathrm{T}^{\mathrm{ind}}\right) \mathbf{I}\left(\right.$ ("is tasty $\left.{ }^{\text {ind" }}, a, c, p\right)=\{x \in \mathrm{D}$ : in $\mathrm{W}(p)$ and at $\mathrm{T}(p), x$ is agreeable to the standard of taste of $\mathrm{S}(c)$ at $\mathrm{T}(c)\}$

[= the set of elements of D that are agreeable to the standard of taste of the agent of $c$ at the time of $c$, in the world of $p$ at the time of $p$ ].

$\left(\mathrm{T}^{\mathrm{rel}}\right) \mathbf{I}($ "is tasty abs", $a, c, p)=\{x \in \mathrm{D}$ : in $\mathrm{W}(p)$ and at $\mathrm{T}(p), x$ is agreeable to the standard of taste of $\mathrm{S}(p)$ at $\mathrm{T}(p)\}$

[ = the set of elements of D that are agreeable to the standard of taste of the agent of $p$ at the time of $p$, in the world of $p$ at the time of $p$ ].

( $\left.\mathrm{T}^{\mathrm{var}}\right) \quad \ldots$ and for all $n \in \mathrm{N}^{16}$ :

I("is tasty ${ }^{\mathrm{var}} x_{n}$ ", $\left.a, c, p\right)=\{x \in \mathrm{D}$ : in $\mathrm{W}(p)$ and at at $\mathrm{T}(p), x$ is agreeable to the standard of taste of $a(n)\}$

[ $=$ the set of elements of D that are agreeable to the standard of taste of the $n$ th object in $a$, i.e. the object assigned to the open variable contained in "is $\operatorname{tasty}^{\mathrm{var}} x_{n}$ " by the assignment function $a$, in the world of $p$ at the time of $p$ ].

\footnotetext{
${ }^{14}$ Kaplan's (1977) points of evaluation are world-time pairs, thus they allow intensions with more finegrained variabilities than points of evaluation that are simply possible worlds, as for example in Stalnaker's work (e.g. 1987). The notion here introduced (world-time-agent triples) allows, but does not require, extensional variation along one more dimension than Kaplan-a possibility Kaplan explicitly envisages in his 1977. Compare Lasersohn 2005, p. 663.

15 The predicate "is tasty" in English is gradable, so there are reasons-in addition to the ones motivating contextualism or relativism - for thinking that "is tasty" is context-sensitive. Many theorists argue that gradable adjectives are doubly context-sensitive: "is tall", for example, has the same contextsensitivities as the more explicit "exceeds the average height in this comparison class by that degree", where "this" and "that" mark the relevant contextual dependencies. See for example Kennedy 1999 and Kennedy and McNally (2005). For simplicity, I am ignoring these considerations in my model-the context-sensitivity is basically still present in the right hand sides of my axioms $\left(\mathrm{T}^{\mathrm{var}}\right),\left(\mathrm{T}^{\mathrm{ind}}\right)$ and $\left(\mathrm{T}^{\mathrm{rel}}\right)$, to the extent to which the meta-language predicate "agreeable" exhibits all the context-sensitivities of gradable adjectives.

${ }^{16} \mathrm{I}$ am assuming that $\mathrm{L}$ contains infinitely many variables $x_{1}, x_{2}, \ldots$ and that each assignment function $a \in \mathrm{A}$ assigns $a(1)$ to $x_{1}, a(2)$ to $x_{2}, \ldots$
} 
The axiom for the predicate "is tasty ${ }^{\text {abs" }}$ is very similar to the above clause (Fre) for "are french": it functions like an ordinary predicate for a temporary contingent property. Consequently, the clause $\left(\mathrm{T}^{\mathrm{abs}}\right)$ employs on its right hand side a metalanguage predicate "tasty"abs" that is supposed to express such a temporary and contingent property. The absolutist might be thought to owe an account of such a property, but this will not concern us right here. The key point is that the predicate "is tasty ${ }^{\text {abs" }}$ does not exhibit any extensional variabilities over and above the kind of index-dependencies exhibited by "are french" as introduced above.

Clauses $\left(\mathrm{T}^{\mathrm{var}}\right),\left(\mathrm{T}^{\mathrm{ind}}\right)$ and $\left(\mathrm{T}^{\mathrm{rel}}\right)$, by contrast, introduce predicates that do exhibit such extra extensional variabilities. Each of the three predicates articulates this variability in terms of the relation of being agreeable borne to the standard of taste of some individual at some time. In the case of "is tasty" ind", this individual and this time is the agent and the time of the context. In the case of "is tasty ${ }^{\text {rel }}$ ", this individual is the agent of the point of evaluation and the time of the point of evaluation. In the case of "is tasty ${ }^{\mathrm{var}} x_{n}$ ", the individual is that assigned by the assignment function to the variable " $x_{n}$ "

Clearly, each of these four predicates could be introduced into a language with a broadly Kaplanian semantics of the kind I have been outlining. The point of debate between absolutists, relativists and contextualists is which of these predicates is a good model of the natural language predicate "is tasty". Each of them favours a different model. In order to answer this question, we will need to consider how a formal semantics like the one outlined can be used to make predictions about the natural language it models, and also how it can be extended to accommodate further expressions and how these would interact with "is tasty ${ }^{\mathrm{var}} x_{n}$ ", "is tasty" ind" and "is tasty $^{\text {rel }}$.

\section{How the Semantics Generates Predictions: principle (KG)}

When using a semantics like the one outlined as a model for a particular natural language, we are in effect making a number of further assumptions (these assumptions, when made explicit, explain in what sense or respect the semantics is a model of, or represents, that language). One central assumption that is usually made is the assumption that each concrete utterance of a sentence is represented by an associated context, the context of that utterance, and that what I have called the "intension" of the sentence at that context-the utterance's semantic content-allows us to make predictions about the truth or otherwise of the utterance. More specifically, the assumption is that the utterance of a sentence is true iff the intension of the sentence at the utterance's context has the value 1 at the point of evaluation determined by that context ${ }^{17}$ :

(K) The utterance $u$ of a sentence $\sigma$ is correct (true)

iff Intension $(\sigma, \mathrm{C}(u))(\mathrm{P}(\mathrm{C}(u)))=1$.

[the intension of $\sigma$ at the context of $u$ has the value 1 at the point of evaluation determined by the context of $u$.]

iff for all $a \in \mathrm{A}, \mathbf{I}(\sigma, a, \mathrm{C}(u), \mathrm{P}(\mathrm{C}(u)))=1$.

[for all assignment functions $a$ : the extension of $\sigma$ at assignment $a$ and the content of $u$ and the point of evaluation of the context of $u$ is 1.]

\footnotetext{
${ }^{17}$ See Kaplan 1977, p. 522f.
} 
$(\mathrm{K})$ is a principle, that connects the semantics of a model language with independently measurable data, namely the truth of natural language utterances: competent users of a natural language will be able to say, on the basis of their linguistic competence, whether a given utterance of a sentence of that language (described in sufficient detail) would be true. ${ }^{18}$ Competent users' judgements of the truth of potential utterances of sentences are taken as manifestations of the semantic properties of sentences of their language, and interpreted theoretically via $(\mathrm{K})$.

$(\mathrm{K})$ is restricted to sentences that do not contain free variables (see the definition of "intension" above). However, the proposal to model "tasty" on "tasty ${ }^{\mathrm{var}} x_{n}$ ", relies on the idea that we use sentences containing free variables, and that the correctness of such utterances depends on the context of use. So we need to offer a more general principle which allows that open formulae are evaluated according to a contextually determined assignment function. ${ }^{19}$ If we write " $\mathrm{A}(x)$ " for "the assignment function determined by context $x$ ", then here is the general principle:

$\left(\mathrm{K}^{\mathrm{G}}\right) \quad$ The utterance $u$ of a sentence $\sigma$ is correct (true)

iff $\mathbf{I}(\sigma, \mathrm{A}(\mathrm{C}(u), \mathrm{C}(u), \mathrm{P}(\mathrm{C}(u)))=1$.

[the extension of $\sigma$ at the assignment determined by the context of $u$, and the content of $u$, and the point of evaluation of the context of $u$ is 1.]

In using $\left(\mathrm{K}^{\mathrm{G}}\right)$ to generate predictions about the truth of a given utterance, a lot will depend on which sentence we take to be the sentence that was uttered, and which context we take to be the context of the utterance (see Predelli 2005). A lot could also depend on which point of evaluation we take to be the one determined by a given context. However, except for a brief re-appearance of the issue in the next section, I shall assume that the point of evaluation $\mathrm{P}(c)$ of a context $c=\langle s, t, l, w\rangle$ is simply $<w$, $t, s>.^{20}$

\section{Assessment of the Four Models}

Let us now consider the differences between the four predicates. The first observation to make is that "is tasty"abs" has the following property: its extension cannot vary from one context to another unless the contexts vary in their world or time parameter. Thus, two utterances of the sentence "Licorice is tasty ${ }^{\text {abs }}$." cannot vary in truth-value (as defined by $\left(\mathrm{K}^{\mathrm{G}}\right)$ ), unless the contexts of these utterances vary with respect to their world or time parameter. A corollary of this is that utterances of the sentence "Licorice is tasty abs." and its negation "Licorice is not tasty ${ }^{\text {abs }}$." cannot (assuming a standard treatment of negation) both be $\left(\mathrm{K}^{\mathrm{G}}\right)$-true unless the utterances vary with respect to their world or time parameter.

It is precisely this property of "is tasty ${ }^{\text {abs" }}$ that has seemed to many theorists to set it apart from "is tasty" in English. There seem to be cases where an utterance by one person of "Licorice is tasty." would be correct, while an utterance of the same sentence by another person would be incorrect (or where an utterance of "Licorice is

\footnotetext{
${ }^{18}$ Compare Carnap 1955 and Stanley 2007, Introduction.

${ }^{19}$ Compare Kaplan 1977, p. 591-2 (“Afterthoughts").

${ }^{20}$ Some filter will be needed to sort those correctness judgements that are taken to reflect the semantics directly (perhaps "literal truth" judgements) from judgements that concern correctness in the sense of compliance with other norms, such as for example pragmatic maxims, prudential requirements or norms of etiquette. These issues concerning the semantics-pragmatics division will have to be left aside in this essay.
} 
not tasty." by the other person would also be correct), without there being a difference in the world of the context or the time of the context that could explain this. But if to make a $\left(\mathrm{K}^{\mathrm{G}}\right)$-untrue utterance is a form of incorrectness, then this is in conflict with the predictions of the semantics.

Anyone accepting the existence of these cases will therefore seek alternative models for the semantics of "is tasty". In particular, since the difference in the range of correct application of "is tasty" is plausibly grounded in personal differences amongst the agents involved, theorists have looked at predicates like "is tasty ${ }^{\text {ind" }}$ or "is tasty ${ }^{\text {rel, }}$, for these would account for the cases just described: since the people making the utterances are different, the agents of the relevant contexts are also different, which in turn means that licorice may be agreeable to the standard of taste of the one, while not being agreeable to the standard of taste of the other agent. In the case of "is tasty ${ }^{\text {ind", }}$, this accounts for the difference in truth-value via the sentence's contextdependence, while in the case of "is tasty ${ }^{\text {rel " }}$ it does so via the sentence's indexdependence.

What about the difference between "is tasty ${ }^{\text {ind" }}$ and "is tasty ${ }^{\text {rel "? }}$. A little reflection will reveal that all the contexts at which it is true (in the sense of $\left(\mathrm{K}^{\mathrm{G}}\right)$ ) to call a thing "tasty" ind" is also a context at which it is true to call it "tasty" rel", and vice versa. If the range of true application of a predicate at a context is the extension it has (for all assignment functions) at that context and that context's point of evaluation, then "is tasty" ind" and "is tasty ${ }^{\text {rel" }}$ have the same range of true application at all contexts. This much follows from our definitions and $\left(\mathrm{K}^{\mathrm{G}}\right)$. So what significance could their difference possibly have?

Suppose the only predictions the semantics yields are predictions as to the $\left(\mathrm{K}^{\mathrm{G}}\right)$ truth of potential utterances. Then the only way in which the difference between "is tasty ${ }^{\text {ind" }}$ and "is tasty ${ }^{\text {rel" }}$ can become predictively significant in our current framework, is by way of expressions with which "is tasty"ind" and "is tasty" rel" could be compounded, and which are either index-shifters without being exactly analogous context-shifters, or vice versa (i.e. expressions that are context shifters without being exactly analogous index-shifters).

For illustration consider the terms "yesterday" ind" and "the-day-before ${ }^{\text {rel", }}$, which are stipulated to have the following semantics:

( $\left.\mathrm{Y}^{\text {ind }}\right)$ For all $a \in \mathrm{A}, c \in \mathrm{C}, p \in \mathrm{P}$ :

I("yesterday" ind", $a, c, p)=\{x \in \mathrm{D}: x=$ the day before the day that includes $\mathrm{T}(c)\}$

( $\left.\mathrm{Y}^{\mathrm{rel}}\right) \quad$ For all $a \in \mathrm{A}, c \in \mathrm{C}, p \in \mathrm{P}$ :

I("the-day-before $\left.{ }^{\text {rel } ", ~} a, c, p\right)=\{x \in \mathrm{D}: x=$ the day before the day that includes $\mathrm{T}(p)\}$

These two expressions, as defined, also have the same range of true application at every context. However, their meaning is significantly different. The first will not be shifted by a temporal intensional operator, while the second will be. Thus, if we assume that "On Wednesday" is a temporal intensional operator (and is not a monster), then the sentences "On Wednesday Peter mentioned yesterday ind." and "On Wednesday Peter mentioned the day before ${ }^{\text {rel }}$." will not be $\left(\mathrm{K}^{\mathrm{G}}\right)$-true at the same contexts. This sort of consideration might persuade us to treat "yesterday" in English 
on the model of "yesterday" ind", and the English phrase "the day before" on the model of "the-day-before" rel".

It is not hard to find candidate intensional expressions that would shift "is tasty" ${ }^{\text {rel }}$, but not "is tasty ind". In Kaplan's original system, there are no expressions that shift the context parameter (there are no "monsters" or "operators on character"). ${ }^{21}$ Given this, any intensional operator that shifts the agent parameter of "is tasty" ${ }^{\text {rel " }}$ would create a context within which "is tasty" ind" and "is tasty" ${ }^{\text {rel" }}$ are not intersubstitutable.

First, consider two paradigmatic intensional contexts: if we treat "believes" and "says" as intensional operators, then it will make a difference whether we embed "is tasty" ${ }^{\text {ind" }}$ or "is tasty ${ }^{\text {rel" }}$ in the scope of "Peter believes/says that ...". Without going into the details of the semantics of belief- and saying-reports, let us suppose that 'Peter believes/says that $\varphi$ ' has value 1 at a context and point of evaluation, just if the intension of $\varphi$ at $c$ is true at all points of evaluation compatible with what Peter believes/says. ${ }^{22}$ Then

$$
\text { "Peter believes/says that licorice is tasty }{ }^{\text {ind }}
$$

would express at a context $c$ an intension that is true at a point $p$ iff for any point $p^{*}$ compatible with what Peter believes at $\mathrm{T}(p)$ and in $\mathrm{W}(p)$ it holds that in $\mathrm{W}\left(p^{*}\right)$ licorice is agreeable to the standard of $\mathrm{S}(c)$ at $\mathrm{T}(c)$. However,

$$
\text { "Peter believes/says that licorice is tasty }{ }^{\mathrm{rel}} \text { ", }
$$

would express at a context $c$ an intension that is true at a point $p$ iff for any point $p^{*}$ compatible with what Peter believes at $\mathrm{T}(p)$ and in $\mathrm{W}(p)$ it holds that in $\mathrm{W}\left(p^{*}\right)$ licorice is agreeable to the standard of $\mathrm{S}(p)$ at $\mathrm{T}(p)$.

It seems that the English

\section{"Peter believes that licorice is tasty"}

behaves the way we stipulated (2) to behave, not (1): the standard of taste of the context's agent at the context's time would seem completely irrelevant for evaluating an utterance of (3). ${ }^{23}$

There are ways for the indexical contextualist to maintain that (1) can nevertheless serve as a model of (3). One of them is to argue that "Peter believes/says that" and similar expressions should (sometimes) be construed as context-shifting operators (monsters). This sort of position would depart from the Kaplanian division of labour between context and point of evaluation, according to which the first is used for unshiftable, while the second is used for shiftable variabilities in extension. Since

\footnotetext{
${ }^{21}$ Kaplan famously thought that "all operators that can be given an English reading are 'at most' intensional” (1977, p. 502, see also p. 510f).

${ }^{22}$ The locus classicus for this sort of treatment is Hintikka 1962. See Stephenson 2007a for a more detailed application to the current debate.

${ }^{23}$ The argument in $\$ 3.3$ of Kölbel 2008a and the "first problem" in $\$ 3$ of Kölbel $2008 \mathrm{~b}$ can be subsumed under this heading. Lasersohn 2005 seems to have considered a similar treatment of taste predicates when embedded in attitude ascriptions, however, phenomena of "exocentric uses" lead him not to treat the judge parameter as being intensionally shiftable. Stephenson (2007a\&b) by contrast uses a similar account of taste-predicates when embedded under "thinks". However, her account models only some occurrences of "tasty" by her complex expression "tastyPROJ", which has the same semantics as "is tasty" ${ }^{\mathrm{rel}}$ " has here.
} 
these operators evidently fail to shift the contextual parameters of some expressions (e.g. "I", "today"), such an account would also need to describe the selectiveness of the shifting.

Another potential operator that would be sensitive to the difference between "is tasty ind" and "is tasty ${ }^{\text {rel" }}$ "would be a complex intensional predicate modifier "for $\alpha$ ", which might be stipulated to have the following properties. ${ }^{24}$

(For) For all $a \in \mathrm{A}, c \in \mathrm{C}, p \in \mathrm{P}$ : if $\alpha$ is a singular term and $\beta$ is a 1-place predicate, then for all $p^{*}$ such that $\mathrm{S}\left(p^{*}\right) \in \mathbf{I}(\alpha, a, c, p)$,

$\mathbf{I}\left({ }^{\prime} \beta\right.$ for $\alpha$ ', $\left.a, c, p\right)=\mathbf{I}\left(\beta, a, c, p^{*}\right)$.

This operator "for $\alpha$ ", when attached to an index-sensitive predicate $\beta$, basically shifts the extension of $\beta$, to the extension it would have at a different point of evaluation, namely one that has the extension of $\alpha$ as its agent. If $\alpha$ is neither contextsensitive nor index-sensitive, then the new complex predicate ' $\beta$ for $\alpha$ ' will lack the index-dependence of the constituent predicate $\beta$. For example, 'is tasty ${ }^{\text {rel }}$ for John' would be an index-insensitive predicate (at least with respect to the agent of the point of evaluation).

If for is used to model the natural language expression "for", as it occurs in

"Licorice is tasty for John."

then "is tasty" rel", would seem the better model for the English "is tasty. ${ }^{25}$ For if "is tasty" was like "is tasty (4), and (4) should continue to exhibit the same context-dependence as "Licorice is tasty.". However, it manifestly does not do that. Conversely, someone favouring "is tasty ind" as a model for "is tasty" might propose an alternative semantics of "for", one according to which it is a context-shifter (monster).

Finally, consider the following English expressions, when uttered in response to an utterance by Peter of "Licorice is tasty.":

(5) That's right.

(6) That's wrong.

(7) Yes.

(8) No.

(9) I/you/John agree(s) with that.

It seems intuitively clear that responses (5)-(9) in some sense pick up the view expressed by the utterance to which they respond. In the case of (5), (6) and (9), the expression "that" seems to refer to something like what was said by the previous utterance, and (7) and (8), respectively, express agreement with what was said by the previous utterance. Unlike "for" and "Peter believes/says that", these expressions do not embed "is tasty" directly. However many theorists are tempted to treat "that", as it

\footnotetext{
${ }^{24}$ Similar operators are considered in Lasersohn 2005, Kölbel 2009 and Kölbel 2011, p. 144.

${ }^{25}$ In Stephenson's $(2007 \mathrm{a} \& \mathrm{~b})$ relativistic model, there is a predicate "tasty" that is a two-place predicate. She analyses many occurrences of English "tasty" as the complex expression "tastyPROJ", which receives the same semantics as "tasty ${ }^{\text {rel" }}$ here. However, this treatment allows her to treat "for", as in "tasty for John" to work like an ordinary preposition, the one needed for the judge argument of the two-place predicate "tasty". See also MacFarlane 2012, who discusses a similar semantics for "tasty to Sam".
} 
occurs in (5), (6) and (9), as anaphorically or demonstratively inheriting the intension of the preceding utterance of "Licorice is tasty.". The interpretation of (7) and (8) seems to be similarly linked to that anaphoric antecedent, (7) expressing acceptance and (8) rejection of the intension of the preceding utterance. This fits well with (a) the plausibility of the thesis that (5)-(9) refer back to what was said in, or the content of, the preceding utterance, and (b) the tradition that treats intensions as the objects of belief and assertion.

This treatment, however, would rule out "is tasty ind" as a model for English "is tasty". The utterers of (5) to (8) do not seem to be accepting or rejecting the intension that "Licorice is tasty" wnd" would have had. If they did they would be accepting/rejecting an intension whose truth-value depends on whether Licorice is agreeable to Peter's standard of taste. But these utterances cannot normally be interpreted like that. Similarly, a response like (9) does not depend on whether the speaker/the audience/John agrees with the proposition that Licorice is agreeable to Peter's standard of taste.

On the other hand, the suggested treatment of (5)-(9) seems to favour "is tasty ${ }^{\text {rel, }}$ as a model: (5) and (7) would seem to be correct when the utterer has a standard of taste to which licorice is agreeable, and (6) and (8) would seem to be correct when the utterer has one that doesn't. The correctness of utterance (9) seems to require that the speaker/the audience/John accept an intension that has value 1 at points where licorice is agreeable to the agent's standard at the time. ${ }^{26}$

As in the case of attitude contexts and "for", the indexical contextualist can devise alternative treatments of the constructions in (5)-(9) in order to save "is tasty ${ }^{\text {ind" }}$ " as the model for English "is tasty". Just as "Peter believes" and "for John" can be treated as context-shifting "monsters", so can (5)-(9): it could be treated as picking up not the intension of "Licorice is tasty" ind" at the context of the preceding utterance, but its intension at a different context-presumably one that differs from the original context by substituting the agent of the context of utterances (5)-(9) for the agent of the original context. This would engender further modifications of the Kaplanian framework we started with. ${ }^{27}$

Much attention is given in the literature to arguments that appeal to purported cases of "faultless disagreement". ${ }^{28}$ It will be helpful to comment briefly on these arguments. The starting point are cases like those used above to undermine absolutism: cases where, for example, there is an utterance of "Licorice is tasty." and also also an utterance of "Licorice is not tasty.", the utterances both seem to be correct performances in every way, but no contextual difference in the world- or time parameter can account for a difference in the extension of "is tasty" from one utterance to the other. As explained above, this is sufficient to motivate contextualism or relativism: both the relativist and the contextualist claim that the two utterances are correct ("faultless"). However, so the argument goes, the speakers of the two utterances seem to disagree with one another, and contextualism predicts that they do not, for contextualism assigns intensions to the two utterances that are compatible

\footnotetext{
${ }^{26}$ Cf Kölbel 2008a, 2009, 2011.

${ }^{27}$ To start with, Kaplan's notion of a context (and the one used above) would have to be changed, for the context-shifting constructions would require contexts with an individually shiftable agent parameter. So we would have to allow contexts $\langle w, s, l, t>$ where $s$ is not in $l$ at $t$. Shifting of individual context parameters would be needed because presumably the contextualist would not want to shift the extension of "that" when someone responds with (5) to an utterance of "That is tasty" ind."

${ }^{28}$ e.g. Kölbel 2003, Lasersohn 2005, MacFarlane 2007, Cappelen \& Hawthorne 2009.
} 
with one another (can be true at the same point, are cotenable). The relativist, by contrast, predicts that the intensions of the two utterances are at least not cotenable, they can't be true at the same point of evaluation, this explaining the impression of disagreement.

The argument has been criticised mainly in three ways: ${ }^{29}$ it has been claimed firstly that non-cotenability is not sufficient for disagreement (witness assertions/beliefs of non-cotenable intensions at different worlds or different times), but that secondly noncotenability is not necessary for disagreement (witness your assertion/belief on Sunday that it is sunny, and my assertion/belief on Monday that it was not sunny the previous day). Others have argued, thirdly, that two assertions/beliefs disagree only if not both of them can be correct. There is an ongoing discussion of the "correct" account of (dis)agreement.

However, the difficulty for the contextualist does not depend on any pretheoretical notion of disagreement. There seems to be a clear sense in which the two parties in the case under discussion are saying things that are not co-tenable: the second utterer cannot rationally accept what the first one has said without changing his or her mind. ${ }^{30}$ This constitutes a difficulty for the contextualist, one that is related to the difficulties with (5)-(9) and the intensional phenomena discussed above. Again, there are ways for the contextualist to explain the impression of non-cotenability by appealing to pragmatic phenomena such as presuppositions or generalized implicatures. ${ }^{31}$

What difficulties do relativists face? The principal difficulty that has been raised involves the assumption (appealed to above) that the intensions of utterances are also the objects of assertions made by means of such utterances, and that they are also the objects of the beliefs that are typically expressed by such assertions and would make them sincere. The worry is that there is no coherent account of belief or assertion according to which the contents of belief and assertion do not have absolute truthvalues. Objections along these lines often go back to Evans' objections to Priorean tensed propositions (Evans 1985). Some have answered that there is no problem as long as utterances are absolutely true/correct or untrue/incorrect (which, given $\left(\mathrm{K}^{\mathrm{G}}\right)$, they are).$^{32}$ Others have elaborated on the role of contents of assertion and belief that do not have absolute truth-values, recently often under the heading of "centered content" or "de se content".33

Finally, let us turn our attention to the free-variable proposal introduced above, the proposal to use "is tasty ${ }^{\mathrm{var}} x_{1}$ " as a model of "is tasty". In the debate about relativism vs contextualism, this option is not usually distinguished clearly from the contextualist who claims that "tasty" is like "tasty ${ }^{\text {cont", }}$ i.e. the contextualist we have been considering up to here. However, it is one of the possible sources of extensional variation that exists in a Kaplanian framework. Stojanovic (2007) defends a version of free-variable contextualism, and a similar position has played a role in a related

\footnotetext{
${ }^{29}$ See e.g. MacFarlane 2007, Stojanovic 2007.

${ }^{30}$ Cf Kölbel 2004, pp. 304-5.

${ }^{31}$ See López de Sa 2007 for a solution in terms of presuppositions. See Kölbel 2007, p. 286-7 for a contextualist answer that explains the existence of such presuppositions as generalized implicatures. See Sundell 2011, going back to Barker 2002, for a different solution in terms of pragmatic negotiation about the context.

${ }^{32}$ e.g. Recanati 2007, Kölbel 2011.

${ }^{33}$ See e.g. Egan 2006, 2007; Kindermann (forthcoming); Kölbel 2002, 2013a\&b; MacFarlane 2003, 2005b, 2008; Moss 2012; Ninan 2010; Torre 2010.
} 
debate..$^{34}$ According to the free-variable-contextualist, a sentence like "Licorice is tasty." is in effect an open sentence, i.e. a sentence that contains an unbound variable. This immediately raises the question how open sentences could be used in communication. ${ }^{35}$ Some theorists (e.g. Stanley and Szabo 2000) claim that unbound variables are like indexicals: they are contextually assigned a semantic value.

In Kaplan's framework, phenomena of context-dependence and phenomena of binding are strictly separated (recall again Kaplan's requirement that there are no context-shifting operators). The fact that some of the parameters of variation under discussion here are clearly shiftable at least motivates the thought that they can't be contextual parameters. The further thought that the shifting is a form of variable binding then leads to "tasty ${ }^{\mathrm{var}} x_{1}$ " as a natural model of "tasty".

Once we use the apparatus of variables to account for phenomena of contextdependence, the question arises whether this apparatus couldn't be used for all context-sensitive expressions, including indexicals, thus allowing us to simplify the semantics by eliminating the context parameter altogether. We would simply have to distinguish bindable from non-bindable variables. Thus, the open-variable approach, while not at all incoherent, seems to lead us away from the Kaplanian framework as I have outlined it. Some may argue that Kaplan's system needs this sort of overhaul anyway. ${ }^{36}$ As interesting as that would be, it would be a new issue that I cannot do justice here. $^{37}$

This concludes my sample assessment of the four different models of the natural language predicate "is tasty". The general shape of the issues is similar in other areas in which contextualism and relativism have been debated (e.g. other evaluative expressions, epistemic modals, probability ascriptions, conditionals, knowledge ascriptions). However this does not mean that the same conclusion should be reached in all these areas, for the syntactic and semantic specifics vary considerably from case to case. ${ }^{38}$

\section{Reasons for Moving Beyond (KG)}

Let us return to assumption $\left(\mathrm{K}^{\mathrm{G}}\right)$, made in $\S 4 .\left(\mathrm{K}^{\mathrm{G}}\right)$ defines what it is for an utterance to be true in terms of the function $\mathbf{I}$ defined by the semantics. In this way $\left(\mathrm{K}^{\mathrm{G}}\right)$ generated predictions as to the truth of utterances-predictions that can be independently corroborated by consulting competent speakers of the language. Now, the definition relied not only on I. It also relied on the idea that each utterance is the utterance of a particular sentence of $\mathrm{L}$, and that one of the contexts in the set $\mathrm{C}$ is the

\footnotetext{
${ }^{34}$ In the debate about "unarticulated constituents", which has some important similarities with the relativism-contextualism debate (see Recanati 2004, 2007), some (e.g. Stanley 2000 and Stanley \& Szabo 2000) claim that certain expressions contain covert variables, i.e. not at the surface, but at the logical form level.

${ }^{35}$ See e.g. Bach 1994, 2001, who defends such a view.

${ }^{36}$ See for example, Lewis 1980 and Stojanovic 2007, who argue for an "index-theory". Lasersohn 2013 argues against points of evaluation (in the presence of "contexts of assessment"), while Schaffer (2012) argues that the only form of extensional variability that we should admit is that of unbound variables.

${ }^{37}$ One final remark: the open variable approach as introduced here, would seem to bear some syntactic similarity with Stephenson's (2007a\&b) and MacFarlane's (2012) relativistic approach: both use a complex predicate as the model for "is tasty", both think that this complex predicate is built from a two-place predicate. Thus both are syntactically more sophisticated than the "tasty" cont"- and the "tasty"rel"-model.

${ }^{38}$ See e.g. Yalcin 2007, who raises difficulties for relativism about epistemic modals that are specific to that case.
} 
context of the utterance. Moreover, $\left(\mathrm{K}^{\mathrm{G}}\right)$ gives a decisive role to the point of evaluation of the context of the utterance.

In some cases, this way of using a semantics to generate predictions concerning correct usage may be thought not to be adequate. In this final section I shall briefly discuss one of these, namely the case of utterances about the contingent future, and then point the reader to a further case that may motivate liberation from $\left(\mathrm{K}^{\mathrm{G}}\right)$.

If we assume that uttering a sentence is true when the intension of the sentence at the context of the utterance has the value 1 at the point of evaluation of that context, then we are a fortiori assuming that each utterance event determines a unique possible world with respect to which the correctness of the utterance is evaluated. Consider an utterance $u_{1}$, made in 2013 , of

\section{(F) In 2014 Germany win the football world cup..$^{39}$}

If $u_{1}$ determined this unique world of evaluation, then the future would not be open during utterance event $u_{1}$. For $u_{1}$ would then be compatible with only one possible way for events to unfold. This seems incompatible with the metaphysical view that the future is open (that we live in a "branching" universe) ${ }^{40}$ Such a view would seem to allow at best that each utterance event $u$ determines a set of possible worlds, namely those that correctly describe the history of $u$ up until $u$, but which lay out different future courses of events. None of the many worlds in this set is privileged as "the way things are going to be", for if that were so, then the future would not be genuinely open.

So, if $\left(\mathrm{K}^{\mathrm{G}}\right)$ cannot serve to generate predictions from the semantics about which utterances are correct, then how can this be done? The first thing to note is that any metasemantic bridge principle, like $\left(\mathrm{K}^{\mathrm{G}}\right)$, that defines an absolute notion of truth for utterances will run into the same problem. For the predictions of truth that such a principle generates will give us the same truth-value for $u_{1}$ independently of whether we evaluate it before or after the world cup. A fortiori this means that the indeterminist should look for a different kind of datum to predict. So as indeterminists we might say that utterances are true or false at or relative to evaluation events. Instead of trying to predict which potential utterances a competent speaker would regard as true (period), we try to predict something more complicated: in which potential evaluation event would a competent speaker evaluate a given potential utterance as true. ${ }^{41}$

\footnotetext{
${ }^{39}$ I have articulated (F) deliberately (and slightly unnaturally) in a timeless present tense in order to demonstrate that the problem I am about to rehearse is independent of questions about the correct treatment of tense in natural language. Thus, the character of $(\mathrm{F})$ is intended to be constant with respect to the time parameter of the context, and the intension of $(\mathrm{F})$ at any context is intended to be constant with respect to the time parameter of the point of evaluation. Nothing but presentational ease hangs on this assumption.

${ }^{40}$ See Belnap et al. 2001, MacFarlane 2003.

${ }^{41}$ In MacFarlane's writings moving away from (K) (i.e. from what MacFarlane would call a standard "post-semantics", and what Recanati (2007) calls "moderate relativism") is an essential ingredient in relativism properly so called. MacFarlane makes this departure in the post-semantics also visible in the semantics proper by adding a "context of assessment" parameter to the standard context of use and point of evaluation. However, the essential point does not require any departure from double-index semantics: a "genuinely relativistic" definition of utterance truth (e.g. (K*) below) can be defined simply on a standard semantics.
} 
Let us say that each evaluation event $e$, just like each utterance event, determines a set of possible worlds, namely the worlds that correctly describe events up to $e$. Let us say further that the possible worlds that correctly describe the history leading up to an event $e$ are the worlds compatible with $e$. As events unfold, worlds still compatible with earlier events fall away and are no longer compatible with later events. We can then speak derivatively of the contexts compatible with an utterance- or evaluation event $e$, namely the set of contexts $\langle w, s, l, t>$, such that $w$ is compatible with $e, s$ is the agent of $e, l$ is the location of $e$ and $t$ is the time of $e$.

For example, the worlds compatible with utterance $u_{1}$, and with any contemporaneous evaluation event $e_{1}$, include worlds in which Germany win in 2014, and also worlds in which they do not. However, an evaluation event $e_{2}$ in autumn 2014 is no longer be compatible with many of these worlds, and in particular it is compatible only with worlds where Germany are the 2014. We should expect that competent judges will give a confident assessment as true only when evaluating utterance $u_{1}$ in an evaluation event like $e_{2}$, while the assessment of $u_{1}$ with respect to $e_{1}$ will not be as confident. Asked about whether $u_{1}$ is true relative to $e_{1}$, competent users will say things like: "That depends on who is going to win." or "Wait until July 2014 and see".

We could then define the truth and falsehood of an utterance at an evaluation event as follows:

(K*) The utterance $u$ of a sentence $\sigma$ is true at an evaluation event $e$ iff for all contexts $c$ that are compatible with $u$ and with $e$ :

Intension $(\sigma, c)(\mathrm{P}(c))=1$.

iff for all $a \in \mathrm{A}, \mathrm{I}(\sigma, a, c, \mathrm{P}(c))=1 .^{42}$

$\left(\mathrm{K}^{*} \neg\right)$ The utterance $u$ of a sentence $\sigma$ is false at an evaluation event $e$

iff for all contexts $c$ that are compatible with $u$ and $e$ :

Intension $(\sigma, c)(\mathrm{P}(c))=0$.

iff for all $a \in \mathrm{A}, \mathrm{I}(\sigma, a, c, \mathrm{P}(c))=0$.

Given these definitions, a given utterance of a sentence may be neither true nor false at some evaluation event. This is as it should be: $u 1$ should be evaluated as neither true nor false at $e 1$. It will be evaluated as true at a future evaluation event like $e 2$ at which the question of who wins in 2014 has been settled.

Clearly, then, it cannot be a requirement for an appropriate utterance of a sentence like $(\mathrm{F})$, that the utterance be true at a concurrent evaluation event, for an utterance like $u 1$ can clearly be appropriate, but is not true (in the sense of $\left(\mathrm{K}^{*}\right)$ ) at any evaluation event in 2013. What, if not truth, one may ask, is the aim of making assertions concerning the contingent future? One answer might be: the aim is to make an utterance that is true with respect to some evaluation event. ${ }^{43}$

Thus, the way a semantics can be used to generate predictions about language use, and thereby to model actual languages, may depart significantly from the simple model $(\mathrm{K})$ adopted by Kaplan and many others, or the more general $\left(\mathrm{K}^{\mathrm{G}}\right)$ adopted here. Another case where such a departure from $\left(\mathrm{K}^{\mathrm{G}}\right)$ may be needed is that of vague

\footnotetext{
${ }^{42}$ For simplicity, I am assuming that we are only considering closed sentences, i.e. sentences without unbound variables.

${ }^{43}$ More could be said about specific conversational or assertoric norms, see, e.g. MacFarlane 2014 or Kölbel 2013b.
} 
expressions. Vague predicates can be seen as having a precise extension only relative to a "precisification" (a form of index-dependence). Again, a non-absolute modification of $\left(\mathrm{K}^{\mathrm{G}}\right)$, or a non-absolute notion of acceptability of utterances, has been argued to help deal with sorites paradoxes. ${ }^{44}$

\section{Conclusion}

There are several ways in which a semantics can model expressions that exhibit some interesting form of extensional variation. In the case of many recently discussed alleged phenomena of extensional variation, theorists have debated the comparative merits of "contextualism" and "relativism", i.e. respectively the view that the variation should be modeled as context-dependence, and the view that it should be modeled as index-dependence. In this essay we have illustrated the issues that arise by comparing various approaches to semantically modelling the natural language predicate "is tasty" within a specific Kaplanian semantic framework, and exemplifying the considerations that can be brought to bear. It emerged that within this specific framework, there were some important consideration in favour of relativism. However, it also became clear that these considerations disappear if one departs from the Kaplanian framework, and that it is an open question what sort of semantic framework is best, and whether we should abandon some of the features of the standard framework, in particular the specific division of labour between the three factors of extensional variation: the assignment of values to variables, the context of use, and the point of evaluation.

Moreover, we saw in $\$ 5$ that independently of the question of context-dependence vs index-dependence vs assignment-dependence, there is the question of whether the we should use an absolute definition of utterance truth in the style of $\left(\mathrm{K}^{\mathrm{G}}\right)$ in order to use the formal semantics to model a particular natural language and the behaviour of its users. In the contemporary debate a negative answer to this question has also been connected with the term "relativism", and we have seen that declarative utterances concerning a contingent aspect of the future (i.e. later than the utterance) may well require such an answer, at least if semantics is to remain neutral with respect to metaphysical questions such as whether the future is genuinely open. ${ }^{45}$

\section{References}

Bach, Kent (1994) Conversational Impliciture. Mind and Language 9, 124-62.

Bach, Kent (2001). You Don't Say? Synthese 128, 15-44.

Barker, Chris (2002). The dynamics of vagueness. Linguistics and Philosophy 25, 136.

Belnap, Nuel, Michael Perloff and Ming Xu (2001) Facing the Future. Oxford: Oxford University Press.

\footnotetext{
${ }^{44}$ Fara 2000 and Kölbel 2010 argue for such a treatment of vague predicates.

${ }^{45}$ I would like to thank many people for comments on this work, in particular the philosophers at the Osnabrück University philosophy colloquium and the participants in the June 2014 meeting of the project Semantic Content and Conversational Dynamics, and two anonymous referees. Special thanks go to Peter Pagin and Kathrin Glüer for excellent editorial advice, as well as very useful and generous comments on multiple versions. The research leading to this article was supported by MICINN, Spanish Government, I+D+i programme, grant FFI2012-37658 and also CONSOLIDER INGENIO Programme, grant CSD2009-0056, which is hereby gratefully acknowledged.
} 
Cappelen, Herman and John Hawthorne (2009) Relativism and Monadic Truth. Oxford: Oxfod University Press.

Carnap, Rudolf (1955) Meaning and Synonymy in Natural Languages. Philosophical Studies 6, pp. 33-47.

Carston, Robyn (2002) Thoughts and Utterances, Oxford: Blackwell.

Chierchia, Gennaro and Sally McConnell-Ginet 2000: Meaning and Grammar, 2nd edition, Cambridge, Mass.: MIT-Press.

Dowell, Janice (2011) A Flexibly Contextualist Account of Epistemic Modals. Philosopher's Imprint 11, no. 14.

Egan, A., J. Hawthorne and B. Weatherson (2005) Epistemic Modals in Context. In G. Preyer and G. Peter (eds), Contextualism in Philosophy, Oxford: OUP.

Egan, Andy (2006) Secondary Qualities and Self-Location. Philosophy and Phenomenological Research 72, 97-119.

Egan, Andy (2007). Epistemic Modals, Relativism and Assertion. Philosophical Studies 133, 1-22.

Egan, Andy (2011) Relativism about Epistemic Modals. In Steven D. Hales (ed), A Companion to Relativism, Oxford: Blackwell.

Egan, Andy (2012) Relativist Dispositional Theories of Value. Southern Journal of Philosophy 50, 557-582.

Evans, Gareth (1985) Does Tense Logic Rest on a Mistake? In his Collected Papers, Oxford: Clarendon Press, pp. 341-63.

Fara, Delia Graff 2000: "Shifting Sands: An Interest-Relative Theory of Vagueness". Philosophical Topics 28, pp. 45-81.

von Fintel, Kai \& Anthony Gillies (2008). CIA Leaks. Philosophical Review 117, pp. 77-98.

Glanzberg, Michael (2007). Context, Content, and Relativism. Philosophical Studies 136, pp. 1-29.

Glanzberg, Michael (2009). Semantics and Truth Relative to a World. Synthese 166, pp. 281-307.

Heim, Irene, \& Angelika Kratzer (1998) Semantics in Generative Grammar. Oxford: Blackwell.

Hintikka, Jaakko (1962) Knowledge and Belief. Ithaca, NY: Cornell University Press.

Kaplan, D. (1977). On Demonstratives. in J. Almog, J. Perry and H. Wettstein (eds), Themes from Kaplan (1989), Oxford: Oxford University Press, 481-563.

Kennedy, Christopher (1999). Projecting the Adjective: The Syntax and Semantics of Gradability and Comparison. New York: Garland Press.

Kennedy, Christopher \& Louise McNally. (2005) Scale Structure, Degree Modification, and the Semantics of Gradable Predicates. Language 81, 345-381.

Kindermann, Dirk (forthcoming) Varieties of Centering and De Se Communication. In Manuel García-Carpintero and Stephan Torre (eds), De Se Thought and Communication, Oxford. 
King, Jeffrey (2003). Tense, Modality, and Semantic Values. Philosophical Perspectives 17, 195-245.

Kölbel, M. (2002). Truth Without Objectivity. London: Routledge.

Kölbel, Max (2003) Faultless Disagreement. Proceedings of the Aristotelian Society $104,53-73$.

Kölbel, Max (2004) Indexical Relativism vs Genuine Relativism. International Journal of Philosophical Studies 12, 297-313.

Kölbel, Max (2007) How to Spell Out Genuine Relativism and How to Defend Indexical Relativism. International Journal of Philosophical Studies 15, 281288.

Kölbel, Max (2008a). Motivations for Relativism. In Manuel Garcia-Carpintero and Max Kölbel (eds.), Relative Truth, Oxford: Oxford University Press, 1-38.

Kölbel, Max (2008b). Truth in Semantics", in Midwest Studies in Philosophy 32, pp. 242-57.

Kölbel, Max (2009). “The Evidence for Relativism”. Synthese

Kölbel, Max (2010) Vagueness as Semantic. In R. Dietz \& S. Moruzzi (eds), Cuts and Clouds: Issues in the Philosophy of Vagueness, Oxford: Oxford University Press, 304-26.

Kölbel, Max (2011). Objectivity, Relativism and Context Dependence. Hagen: Fernuniversität Hagen. Available at: http://www.ub.edu/grc_logos/files/user126/1343744586ObjectivityRelativismContextDependence.pdf

Kölbel, Max (2013a) Agreement and Communication. Erkenntnis.

Kölbel, Max (2013b) The Conversational Role of Centered Contents. Inquiry 56, $97-$ 121.

Lasersohn, Peter (2005) Context Dependence, Disagreement, and Predicates of Personal Taste. Linguistics and Philosophy 28, 643-86.

Lasersohn, Peter (2008) Quantification and Perspective in Relativist Semantics. Philosophical Perspectives 22, 305-37.

Lasersohn (2013) Non-World Indices and Assessment-Sensitivity. Inquiry 56, $122-$ 148.

Lewis, David (1970). General Semantics. Synthese 22, pp. 18-67.

Lewis, David (1980). Index, Context, and Content, in Stig Kanger and Sven Öhman (eds.), Philosophy and Grammar, Dordrecht: Reidel. Reprinted in Lewis 1998.

Lewis, David (1998). Papers in Philosophical Logic, Cambridge: Cambridge University Press.

Lopez de Sa, Dan (2007) The Many Relativisms and the Question of Disagreement. International Journal of Philosophical Studies 15, 269 - 279.

MacFarlane, John (2003) Future Contingents and Relative Truth. Philosophical Quarterly 53, 321-36. 
MacFarlane, John (2005a) The Assessment Sensitivity of Knowledge Attributions. In Tamar Szabo Gendler and John Hawthorne (eds.), Oxford Studies in Epistemology 1, Oxford: Oxford University Press, pp.197-233.

MacFarlane, John (2005b) Making Sense of Relative Truth. Proceedings of the Aristotelian Society 105, 321-39.

MacFarlane, John (2007) Relativism and Disagreement. Philosophical Studies 132, $17-31$.

MacFarlane, John (2008) Truth in the Garden of Forking Paths, in Max Kölbel and Manuel García-Carpintero (eds.), Relative Truth, Oxford: Oxford University Press.

MacFarlane, John (2011) Epistemic Modals are Assessment-Sensitive. In Brian Weatherson and Andy Egan (eds.), Epistemic Modals, Oxford: Oxford University Press.

MacFarlane, John (2012) Relativism. In Delia Graff Fara and Gillian Russell (eds.), The Routledge Companion to the Philosophy of Language, London: Routledge, 132-142.

MacFarlane, John (forthcoming). Assessment sensitivity: relative truth and its applications.

Moss, Sarah (forthcoming). Updating as Communication. Philosophy and Phenomenological Research.

Ninan, Dilip (2010). De Se Attitudes: Ascription and Communication. Philosophy Compass 5, 551-67.

Predelli, Stefano (2005) Context: Meaning, Truth and the Use of Language, Oxford: Oxford University Press.

Recanati, François (2004). Literal Meaning. Cambridge: Cambridge University Press.

Recanati, François (2007) Perspectival Thought. Oxford: Oxford University Press.

Sainsbury, Mark (2005) Reference without Referents. Oxford: Oxford University Press.

Schaffer, Jonathan (forthcoming) "Necessitarianism". Synthese.

Stalnaker, Robert (1987) Inquiry. Cambridge, MA: MIT-Press.

Stanley, Jason (2000). Context and Logical Form”. Linguistics \& Philosophy 23: 391434.

Stanley, Jason (2007) Language in Context: Selected Essays. Oxford: Oxford University Press.

Stanley, Jason and Zoltan Szabó (2000) On Quantifier Domain Restriction. Mind and Language 15, 219-261.

Stephenson, Tamina (2007a) Towards a Theory of Subjective Meaning. Ph.D. Thesis, MIT.

Stephenson, Tamina (2007b) Judge dependence, epistemic modals, and predicates of personal taste. Linguistics and Philosophy 30, 487-525. 
Stephenson, Tamina (2010). Control in Centred Worlds. Journal of Semantics 27, 409-36.

Stojanovic, Isidora (2007). Talking about taste: disagreement, implicit arguments, and relative truth. Linguistics and Philosophy 30, 691-706.

Sundell, Tim (2011) Disagreements about Taste. Philosophical Studies 155, 267-288.

Torre, Stephan (2010) Centered Assertion. Philosophical Studies 150, 97-114.

Westerståhl, Dag (2012) Compositionality in Kaplan-style Semantics. E. Machery, W. Hinzen and M. Werning (eds), Oxford Handbook of Compositionality, Oxford: Oxford University Press.

Yalcin, Seth (2007) Epistemic Modals. Mind 116, 983-1026. 